\title{
Sifat Machiavillan, Komitmen Profesional Mahasiswa Terhadap Intensi Kecurangan Dengan Jenis Kelamin Sebagai Variabel Moderasi
}

\section{Bill Enus Mauboy dan David Adechandra Ashedica Pesudo}

Fakultas Ekonomika dan Bisnis Universitas Kristen Satya Wacana (UKSW) Salatiga

Jl. Diponegoro No. 52-60, Salatiga, 50711, Indonesia

\section{Info Article}

Keywords:

Academic Fraud Intention; Gender; Machiavellian Nature, and Professional Commitment.

ISSN (print) : 2598-7763 ISSN (online): 2598-7771

$\triangle$ Corresponding Author: Bill Enus Mauboy:

Tel. /Fax. +62 823-1371-8606

E-mail: mauboybill30@gmail.com

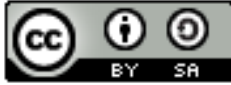

\begin{abstract}
Abtract
Cheating is usually the most common we encounter in the business world, but we do not rule out the possibility of cheating we can also find in the world of education. This study aims to analyze the effect of machiavellian traits, professional commitment, and gender as moderating variables on academic cheating intentions. This research was conducted at the Satya Wacana Christian University's economics and business faculty with purposive sampling techniques. The analysis technique used is multiple regression analysis and moderation analysis techniques. The results of this study indicate that machiavellian traits have a positive effect on academic cheating intentions, and professional commitment does not affect the intention of academic fraud. Besides, gender also weakens the machiavellian relationship and professional commitment to academic cheating intentions
\end{abstract}

Citation: Mauboy, Enus Bill dan Pesudo, Adechandra Ashedica, David. (2019). Sifat Machiavilan, Komitmen Profesional Mahasiswa Terhadap Intensi Kecu-rangan Dengan Jenis Kelamin Sebagai Variabel Moderasi. Accounting and Financial Review, 2 (2)

\begin{abstract}
Abstraks
Kecurangan biasanya paling sering ditemui dalam dunia bisnis, namun tidak menutup kemungkinan kecurangan juga bisa ditemukan dalam dunia pendidikan. Penelitian ini bertujuan untuk menganalisis pengaruh sifat machiavellian, komitmen profesional, dan jenis kelamin sebagai variabel moderasi terhadap intensi kecurangan akademik. Penelitian ini dilakukan di fakultas ekonomika dan bisnis Universitas Kristen Satya Wacana dengan teknik pengambilan sampel secara purposive. Teknik analisis yang digunakan yaitu analisis regresi berganda dan teknik analisis moderasi. Hasil penelitian ini menunjukkan bahwa sifat machiavellian berpegaruh positif terhadap intensi kecurangan akademik, dan komitmen profesional tidak berpengaruh terhadap ntensi kecurangan akademik. Selain itu, jenis kelamin juga malah memperlemah hubungan sifat machiavellian dan komitmen profesional terhadap intensi kecurangan akademik
\end{abstract}

JEL Classification: G20, M42, M14

DOI: https:/ / doi.org/10.26905/afr.v2i2.3727

\section{PENDAHULUAN}

Kecurangan merupakan suatu tindakan yang dengan sengaja melanggar sistem pengendalian. Kecurangan secara umum sering ditemukan dalam dunia bisnis, tapi tidak menutup kemungkinan kecurangan juga terjadi pada dunia akademik (Nurharjanti, 2017). Fitriana dan Baridwan (2012) Kecurangan dalam bidang akademik dapat dipahami sebagai suatu pelanggaran terhadap sistem pengendalian akademik. Sistem pengendalian dalam bidang akademik diantaranya adalah aturan-aturan yang berlaku di lingkungan akademik. Beberapa bentuk pelanggaran sistem pengendalian dalam bidang akademik yang ditemukan pada mahasiswa diantaranya adalah mencontek saat ujian, membawa cheating sheet pada saat tes, atau bahkan mem-buka gadget pada 


\section{Sifat Machiavilan, Komitmen Profesional Mahasiswa Terhadap Intensi Kecurangan Dengan Jenis Kelamin Sebagai Variabel Moderasi \\ Bill Enus Mauboy dan David Adechandra Ashedica Pesudo}

saat tes berlangsung (Santoso, 2015). Perilakuperilaku ini tidak dapat diterima karena telah melanggar aturan-aturan akademik. Menurut Tarbiyah, dkk. (2013) Academic fraud merupakan tindakan tidak etis yang melanggar aturan-aturan berlaku dan dilakukan oleh mahasiswa atau pelajar. Mahasiswa (calon akuntan) juga tidak terhindar dari yang namanya kecurangan. Mahasiswa melakukan kecurangan akademik antara lain kecurangan terhadap aturan-aturan dalam mengerjakan tugas maupun ujian, membantu mahasiswa lain dalam mengerjakan tugas maupun ujian, dan plagiarism (Tarbiyah, dkk., 2013).

Kecurangan dapat timbul salah satunya karena ada intensi (niat) dari pelakunya. Intensi kecurangan sendiri merupakan motivasi yang timbul dari individu maupun kelompok untuk melakukan perilaku yang dipilihnya, jadi ketika individu dihadapkan dengan peluang maka intensi untuk melakukan semakin besar (Simamora, Utami dan Wacana, 2017). Dalam penelitian Riyanti (2015) juga mengemukakan bahwa intensi kecurangan adalah niatan seseorang atau kelompok untuk melakukan kecurangan dengan perilaku-perilaku yang tidak sesuai dengan aturanaturan yang ada.

Terkait dengan intensi kecurangan akademik, terdapat beberapa faktor yang dapat mempengaruhi seperti sifat Machiavellian dan komitmen profesional dengan jenis kelamin sebagai variabel moderasi. Sifat machiavellian dan komitmen profesional dapat mempengaruhi intensi kecurangan karena sifat machiavellian memiliki pemikiran untuk menggunakan berbagai cara untuk mendapatkan keinginan pribadi (Bulutoding, dkk, 2014). Penelitian Sedangkan komitmen profesional berpengaruh karena seorang individu ketika memi-liki komitmen dalam bertindak dan bertanggung jawab sesuai dengan peraturanperaturan yang berlaku sesuai dengan profesi yang dijalani (Aji, 2013). Jenis kelamin berpengaruh terhadap intensi kecurangan karena dalam penelitian yang dilakukan Tangkudung (2014) mendapati bahwa individu dengan jenis kelamin laki-laki lebih cepat beradaptasi dengan budaya setempat dari-pada perempuan. Laki-laki juga lebih cepat menyesuaikan dalam proses belajar mengajar dibandingkan perempuan. Namun penelitian yang dilakukan Sarkawi (2015) menemukan bahwa dalam penilaian budaya lingkungan tidak ada perbedaan yang signifikan antara laki-laki maupun perempuan.

Survey mengenai kecurangan akademik su- dah pernah dilakukan di Indonesia oleh Litbang Media Grup pada tahun 2007. Hasil survey menunjukkan 70 persen pelajar, baik di sekolah maupun tingkat universitas melakukan kecurangan akademik yaitu menyontek.

Penelitian ilmiah sebelumnya terkait intensi kecurangan sudah pernah dilakukan diantaranya penelitian yang dilakukan Simamora, Utami dan Wacana (2017) bahwa intensi kecurangan pelaporan keuangan memiliki hubungan yang positif terhadap sistem pengendalian, dengan begitu maka apabila sistem pengendaliannya lemah, maka intensi kecurangan pun akan meningkat. Penelitian yang dilakukan Riyanti (2015) juga berpendapat bahwa intensi kecurangan (mencontek) dilatarbelakangi oleh beberapa faktor diantaranya sikap, norma subjektif dan kontrol dari individu tersebut. Jenis kelamin sebagai variabel moderasi dapat berdampak memperkuat ataupun memperlemah variabel terikat yaitu kecurangan akademik. Menurut penelitian yang dilakukan Marlina (2017) perempuan dipandang lebih mengikuti aturan yang ada dibandingkan laki-laki. Hal ini dikarenakan perempuan lebih menggunakan sisi sensitifitasnya (feminim) yang lebih tinggi dibandingkan dengan laki-laki (maskulin). Pada survei yang dilakukan Pew Research (2017) memaparkan bahwa 76\% laki-laki yang memiliki kepribadian maskulin lebih tertekan untuk berhasil dalam lingkungan pendidikan, sedangkan untuk perempuan dengan sifat feminim cuma $40 \%$ yang merasa bahwa tekanan tersebut diberikan kepada mereka. Dengan hasil yang tidak konsisten ini maka peneliti ingin mengetahui apakah jenis kelamin dapat memoderasi hubungan sifat machiavellian dan komitmen profesional terhadap intensi kecurangan.

Dengan penjelasan sebelumnya, peneliti memilih objek penelitian yaitu mahasiswa Program Studi S1 Akuntansi Fakultas Ekonomika dan Bisnis Universitas Kristen Satya Wacana. Alasan peneliti memilih objek mahasiswa karena adanya persepsi bahwa apakah mahasiswa benarbenar mendapatkan prestasi dengan cara yang jujur? Atau hanya sekadar hanya ingin mencari nilai dengan menggunakan cara yang tidak jujur.

Berdasarkan pemaparan tersebut, mka tujuan penelitian ini untuk mengetahui apakah sifat machaivellian dan komitmen profesional berpengaruh terhadap intensi kecurangan akademik. Adapun manfaat dari penelitian adalah bagi Akademisi dan instansi. Bahwa dalam penerapannya diharapkan merupakan tambahan informasi dan 
juga bahan kajian untuk ilmu auditing khususnya dalam menganalisis niatan dalam melakukan kecurangan, dan dapat memberikan bukti empiris apakah sifat individu dan komitmen dapat mempengaruhi niatan seseorang dalam melakukan kecurangan.

\section{PENGEMBANGAN HIPOTESIS}

Paham machiavellianism pertama kali dikemukakan oleh Nicolo Machiavelli (1469-1527). Machiavellianisme merupakan sebuah proses dimana seseorang melakukan segala cara (memanipulasi) untuk memenuhi kebutuhan pribadi. Seorang machiavellian tidak memiliki moralitas konvensional namun memilki kecenderungan untuk mengontrol dan mempengaruhi orang lain (Widyaningrum \& Sarwono, 2012). Sifat machiaveliian dapat mempengaruhi intensi kecurangan karena sifat machiavellian memiliki pemikiran untuk menggunakan berbagai cara untuk mendapatkan keinginan pribadi dan semakin tinggi sifat machiavellian, maka semakin tinggi intensi untuk melakukan kecurangan. Pada penelitian Bulutoding (2014) menjelaskan bahwa individu dengan sifat machiavellian tinggi cenderung tidak berperilaku etis, dalam artian individu yang memiliki sifat machiavellian tinggi cenderung untuk mengutamakan kepentingan pribadi dan lebih memiliki keinginan untuk tidak mengikuti aturan. Penelitian Widyaningrum (2012) juga memaparkan bahwa semakin tinggi sifat Machiavellian seorang mahasiswa akuntan maupun akuntan maka dengan demikian semakin tinggi juga kecenderungan melakukan tindakan-tindakan yang secara etis tidak sesuai. Penelitian selanjutnya mengenai sifat machaivellian juga dilakukan Nugraha (2017) menyatakan pribadi Machiavellian akan melakukan tindakan dengan memperhitungkan keuntungan ekonomi yang didapat sebagai landasan dalam bertindak.

$\mathrm{H}_{1}$ : Sifat Machiavelian berpengaruh positif terhadap Intensi kecurangan

Komitmen profesional dapat dipahami sebagai tingkat loyalitas seorang individu pada profesi yang dijalaninya seperti yang telah dipandang oleh individu tersebut (Edwy, 2016). Komitmen profesional memiliki hubungan terhadap intensi kecurangan yaitu ketika seorang individu memiliki sebuah komitmen, maka mereka cenderung untuk tidak melakukan kecurangan. Hal ini dikarenakan ketika seseorang sudah berkomitmen, maka mereka akan menaati aturan-aturan yang berlaku. Pada penelitian yang dilakukan Aji
(2013) memaparkan ketika seorang individu memiliki komitmen profesional yang tinggi, maka individu tersebut cenderung untuk melakukan perilaku etis. Agar individu dapat berprilaku dengan baik, maka individu harus mempertahankan etika profesional yang diatur dalam kode etik maupun mematuhi aturan-aturan yang berlaku. Penelitian yang dilakukan Amalia (2015) mengemukakan individu dengan komitmen profesional yang tinggi cenderung untuk bersikap etis. Dengan demikian intensi untuk melakukan kecurangan juga kecil. Penelitian Nugraha (2017) juga memaparkan komitmen profesional berpengaruh terhadap perilaku etis auditor. Auditor akan berperilaku sesuai dengan tugasnya, yaitu mengedepankan kepentingan publik.

$\mathrm{H}_{2}$ : Komitmen profesional berpengaruh negatif terhadap Intensi kecurangan

Pada studi yang dilakukan Sarkawi memaparkan bahwa jenis kelamin merupakan pembawaan secara biologis yang dibawah sejak lahir dan tidak bisa diubah. Sedangkan gender merupakan perbedaan yang nampak antara perempuan dan laki-laki dalam pandangan nilai maupun perilaku (Sarkawi, 2015). Konsep jenis kelamin lebih mengarah secara demografi yaitu manusia atau individu yang berjenis kelamin lakilaki maupun perempuan dapat diidentifikasi melalui alat kelamin dan peran seksualnya. Hal ini dapat diartikan bahwa atribut tersebut secara fungsional tidak dapat dipertukarkan.

Penelitian terkait jenis kelamin mendapati hasil yang beragam. Diantaranya pada penelitian yang dilakukan Tangkudung (2014) mendapati bahwa individu dengan jenis kelamin laki-laki lebih cepat beradaptasi dengan budaya setempat daripada perempuan. Laki-laki juga lebih cepat menyesuaikan dalam proses belajar mengajar dibandingkan perempuan. Penelitian yang dilakukan Dhinata (2017) juga mendapatkan hasil bahwa individu dengan jenis kelamin laki-laki lebih loyal dari pada perempuan dalam hal kepuasan pelanggan oleh-oleh khas Bali.

Berdasarkan penjelasan di atas, penelitian ini dimaksudkan untuk menguji interaksi yaitu jenis kelamin terhadap sifat machiavellian dan komitmen profesional mempengaruhi intensi kecurangan, maka hipotesis yang diajukan adalah:

$\mathrm{H}_{3}$ : Jenis Kelamin memoderasi pengaruh sifat machiavellian dan komitmen profesional terhadap intensi kecurangan

$\mathrm{H}_{4}$ : Jenis Kelamin memoderasi pengaruh komitmen profesional terhadap intensi kecurangan 


\section{Sifat Machiavilan, Komitmen Profesional Mahasiswa Terhadap Intensi Kecurangan Dengan Jenis Kelamin Sebagai Variabel Moderasi \\ Bill Enus Mauboy dan David Adechandra Ashedica Pesudo}

\section{DATA AND METODE}

Jenis penelitian yang dilakukan adalah kuantitatif, yang bertujuan untuk menekankan pada pengujian teori-teori melalui pengukuran variabel-variabel dengan angka dan akan dianalisis dengan prosedur statistik. Adapun jenis data yang digunakan dalam penelitian ini adalah data primer yaitu data yang diperoleh langsung dari responden yaitu mahasiswa Akuntansi Fakultas

Tabel 1. Operasionalisasi Variabel

\begin{tabular}{|c|c|c|c|}
\hline Variabel & Definisi Operasional & Indikator & Skala Pengukuran \\
\hline Sifat Machiavellian & $\begin{array}{l}\text { Machiavellianisme didefinisikan se- } \\
\text { bagai keyakinan atau persepsi ten- } \\
\text { tang hubungan antar personal yang } \\
\text { mendasari perilaku dalam berhub- } \\
\text { ungan dengan orang lain (Widya- } \\
\text { ningrum \& Sarwono, 2012). }\end{array}$ & $\begin{array}{ll}\text { a. } & \text { Manipulatif } \\
\text { b. Afeksi } \\
\text { c. Ego } \\
\text { d. Agresif } \\
\text { e. Idealogis }\end{array}$ & 5 poin skala Ordinal \\
\hline $\begin{array}{l}\text { Komitmen } \\
\text { Profesional }\end{array}$ & $\begin{array}{l}\text { Komitmen profesional dibentuk pada } \\
\text { saat suatu individu mulai memasuki } \\
\text { suatu profesi yaitu meliputi sesuatu } \\
\text { yang dipercaya, sesuatu yang dite- } \\
\text { rima, tujuan dan nilai-nilai dari suatu } \\
\text { profesi (Aji, 2013). }\end{array}$ & $\begin{array}{l}\text { a. Menjaga nama baik Fakul- } \\
\text { tas maupun Universitas. } \\
\text { b. Kebanggan sebagai maha- } \\
\text { siswa akuntansi. } \\
\text { c. Pandangan atas karir } \\
\text { yang telah dipersiapkan } \\
\text { setelah lulus. }\end{array}$ & 5 poin Skala Ordinal \\
\hline Intensi Kecurangan & $\begin{array}{l}\text { Intensi atau niatan kecurangan yaitu } \\
\text { niat individu untuk melakukan tin- } \\
\text { dakan kecurangan (Riyanti, 2015) }\end{array}$ & $\begin{array}{l}\text { a. Kemungkinan untuk ma- } \\
\text { hasiswa melakukan kecu- } \\
\text { rangan bila ada kesem- } \\
\text { patan. } \\
\text { b. Kemungkinan untuk ma- } \\
\text { hasiswa melakukan kecu- } \\
\text { rangan bila ada tekanan. }\end{array}$ & 5 poin skala Ordinal \\
\hline Jenis Kelamin & $\begin{array}{l}\text { Jenis Kelamin yaitu perbedaan secara } \\
\text { demografi antara laki-laki dan pe- } \\
\text { rempuan. }\end{array}$ & $\begin{array}{l}\text { 0. Laki-laki } \\
\text { 1. Perempuan }\end{array}$ & Skala Nominal \\
\hline
\end{tabular}

Ekonomika dan Bisnis Universitas Satya Wacana. Teknik pengumpulan data dalam penelitian ini menggunakan kuesioner.

Variabel dalam penelitian ini terdiri dari sifat Machiavellian, komitmen profesional, intensi kecurangan dan jenis kelamain. Operasionalisasi variabel di sajikan pada tabel 1 .
Populasi penelitian ini adalah mahasiswa Akuntansi Fakultas Ekonomika dan Bisnis Universitas Satya Wacana. Teknik pengambilan sampel menggunakan purposive sampling. Alasan peneliti menggunakan teknik tersebut karena ada pertimbangan bahwa sampel berada antara semester III sampai dengan semester VII atau minimal sudah atau sedang mengambil kelas pengauditan. Dengan alasan demikian, peneliti berasumsi bahwa sampel sudah memiliki komitmen akan profesi yang dijalani yaitu sebagai mahasiswa akuntansi. Dengan begitu, peneliti mendapatkan angkatan yang aktif dan sesuai dengan kriteria tersebut sebanyak 445 mahasiswa. Untuk mendapakan jumlah sample yang representatif terhadap populasi maka peniliti menggunakan rumus Slovin. Jumlah sampel sebanyak 82 ma- hasiswa.

Adapun jenis data yang digunakan dalam penelitian ini adalah data primer yaitu data yang diperoleh langsung dari responden yaitu mahasiswa Akuntansi Fakultas Ekonomika dan Bisnis Universitas Satya Wacana. Teknik pengumpulan data dalam penelitian ini menggunakan kuesioner.

Penelitian ini menggunakan analisis regresi berganda dan analisi regresi moderated. Analisis regresi berganda digunakan untuk menganalisa hubungan antara variabel indipenden dan dependen, sedangkan analisis regresi moderated digunakan untuk menganalisa hubungan dengan adanya variabel moderasi (memperkuat atau memperlemah). Pengelolaan data dalam penelitian ini menggunakan program SPSS. Adapun persama- 
annya sebagai berikut:

$$
Y=\alpha+\beta_{1} X_{1}+\beta_{2} X_{2}+\beta_{2} X_{a}+e
$$

Keterangan: $Y=$ Intensi Kecurangan, $\alpha=$ Kons-tanta; $\beta=$ Koefisien Regresi; X1 =Sifat Machiavellian; X2= Komitmen Profesional; X3 = Variabel Gender; e = Error

\section{HASIL}

Berdasarkan hasil pengujian variabel sifat machiavellian (X1) menunjukkan bahwa dari seluruh item (10 butir) pertanyaan dalam kuesioner yang digunakan sebagai alat ukur variabel Intensi Kecurangan (Y) ternyata semua item pertanyaan memiliki nilai di atas batas kritis yang ditentukan, sehingga semua item dinyatakan valid. Variabel Komitmen Profesional (X2) juga menunjukkan bahwa dari seluruh item (8 butir) pertanyaan dalam kuesioner yang digunakan sebagai alat ukur variabel Intensi Kecurangan $(\mathrm{Y})$ didapati bahwa semua item pertanyaan memiliki nilai di atas batas kritis yang ditentukan, sehingga semua item di- nyatakan valid. Demikian juga variabel Intensi Kecurangan (Y) juga menunjukkan bahwa dari seluruh item (7 butir) pertanyaan dalam kuesioner yang digunakan sebagai alat ukur variabel Intensi Kecurangan $(\mathrm{Y})$ ternyata semua item pertanyaan memiliki nilai di atas batas kritis yang ditentukan, sehingga semua item dinyata-kan valid.

Berdasarkan hasil pengujian Reliabilitas nilai cronbach alpha lebih besar dari 0,6. Sehingga dapat diambil keputusan instrumen reliabel. Berdasarkan hasil pengujian validitas dan reliabilitas, maka kuesioner penelitian dapat digunakan.

\section{Hasil Penyebaran Kuisioner}

Peneliti memutuskan untuk membagikan kuisioner dengan jumlah 82 kuisioner yang diperlukan., terdiri dari 17 mahasiswa angkatan 2017 dan sisanya 65 mahasiswa merupakan angkatan 2016. Peneliti sengaja menyebarkan sebanyak 115 kuisioner karena untuk mengantisipasi kurangnya data yang disebabkan oleh ketidaklengkapan data maupun pengisian jawaban pada lembar kuisioner. Dengan demikian, kuisioner yang dibagikan tetap memenuhi sejumlah kuisioner yang dibutuhkan untuk pengolahan data. Berikut adalah gambaran umum berdasarkan jenis kelamin yang disajikan dalam tabel 2.

Berdasarkan data pada tabel 2, dapat diketahui bahwa responden perempuan lebih banyak dari pada laki-laki, yaitu sebanyak 58 orang (71,6\%). Namun belum dapat disimpulkan bahwa responden perempuan memiliki niatan dalam melakukan kecurangan lebih besar daripada responden laki-laki.

Tabel 2 Responden berdasarkan Jenis Kelamin

\begin{tabular}{ccc}
\hline Jenis Kelamin & $\begin{array}{c}\text { Jumlah } \\
\text { Responden }\end{array}$ & Presentase \\
\hline Laki-laki & 24 & $28,4 \%$ \\
Perempuan & 58 & $71,6 \%$ \\
Total & 82 & $100 \%$ \\
\hline
\end{tabular}

Berdarkan hasil pengujian normalitas data menujnukkan data berdisitribusi normal. Hal ini ditunjukkan dengan nilai signifikansi sebesar 0,504 pada Uji Kolmogorov-Smirnov (KS) berada diatas angka syarat distribusi data residual yaitu sebesar 0,05

Tabel 3 Hasil Analisis Regresi

\begin{tabular}{lccc}
\hline \multicolumn{1}{c}{ Variabel } & Koefisien & Nilai t & Signifikansi \\
\hline SM -> IK & 0,208 & 2,131 & 0,036 \\
KP -> IK & $-0,175$ & $-1,184$ & 0,240 \\
SM*JK -> IK & 0,008 & 0,201 & 0,841 \\
KP*JK-> IK & 0,008 & 0,186 & 0,853 \\
\hline
\end{tabular}

Berdasarkan tabel 3 menunjukkan tingkat signifikansi dari variabel sifat machiavellian sebesar 0,036 yang berarti lebih kecil dari 0,05. Hal ini berarti sifat machiavellian memiliki pengaruh yang signifikan terhadap intensi kecurangan. Hasil uji $\mathrm{t}$ untuk hipotesis selanjutnya yaitu komitmen profesional memiliki tingkat signifikansi sebesar 0,240 yang artinya lebih besar dari 0,05. Dengan demikian komitmen profesional tidak memiliki pengaruh terhadap intensi kecurangan atau hipotesis kedua ditolak. Pada variabel moderasi memiliki pengaruh terhadap hubungan antara variabel independen dan dependen. Angka signifikansi pada variabel sifat Machiavellian mengalami kenaikan dari 0,036 menjadi 0,240, dimana variabel jenis kelamin memperlemah hubungan antara kedua variabel tersebut. Selanjutnya angka signifikansi pada variabel komitmen profesional juga mengalam kenaikan dari 0,240 menjadi 0,853 . Kenaikan angka signifikansi pada kedua variabel tersebut juga membuktikan bahwa variabel jenis kelamin memperlemah hubungan antara variabel dependen dan independen.

\section{PEMBAHASAN}

Hasil pengujian menunjukkan bahwa sifat Machiavellian berpengaruh terhadap intensi kecurangan akademik. Hal ini sesuai dengan penelitian Bulutoding (2014) yang menyatakan sifat machiavellian berpengaruh negatif terhadap perilaku etis auditor, semakin tinggi sifat machia- 


\section{Sifat Machiavilan, Komitmen Profesional Mahasiswa Terhadap Intensi Kecurangan Dengan Jenis Kelamin Sebagai Variabel Moderasi \\ Bill Enus Mauboy dan David Adechandra Ashedica Pesudo}

vellian seorang auditor maka tingkat perilaku etis auditor semakin rendah. Penelitian yang dilakukan Yuliana (2012) juga mengemukakan bahwa semakin tinggi sifat machiavellian maka perilaku etis seorang individu akan semakin rendah. Sifat Machiavellian adalah sifat sinisme, pragmatis, dan cenderung bersikap manipulatif untuk untuk kepentingan pribadi dimana hal ini dibuktikan dengan signifikansi pada pengujian hipotesis. Semakin tinggi sifat Machiavellian seorang mahasiswa, maka semakin tinggi kecenderungan untuk bertindak curang secara akademis. Dengan demikian, mahasiswa dengan tingkat machiavellian yang tinggi cenderung menggunakan perilakuperilaku tidak etis untuk mendapatkan nilai yang tinggi maupun prestasi.

Hasil pengujian mengemukakan bahwa komitmen profesional tidak berpengaruh terhadap intensi kecurangan akademik. Hal ini juga sesuai dengan penelitian yang dilakukan Aji (2013) yang mengemukakan komitmen profesional tidak berpengaruh terhadap kinerja internal auditor. Berdasarkan penelitian yang dilakukan Wirakusuma (2014) juga mendapatkan hasil yang sama bahwa komitmen profesional tidak berpengaruh kepuasan kerja auditor, hal ini dikarenakan komitmen profesional sangat dipengaruhi oleh organisasi tempat auditor bekerja. Komitmen profesional tidak berpengaruh terhadap intensi kecurangan karena ketika seorang individu memiliki sebuah komitmen, maka mereka cenderung untuk tidak melakukan kecurangan. Hal ini dikarenakan ketika seseorang sudah berkomitmen, maka mereka akan menaati aturan-aturan yang berlaku. Penelitian yang dilakukan Amalia (2015) mengemukakan individu dengan komitmen profesional yang tinggi cenderung untuk bersikap etis. Dengan demikian intensi untuk melakukan kecurangan juga kecil. Penelitian Nugraha (2017) juga memaparkan komitmen profesional berpengaruh terhadap perilaku etis auditor Mahasiswa belum memiliki komitmen yang kuat dalam bidang akademik karena tertekan untuk sukses dalam bidang akademik karena tuntutan orang tua maupun tuntutan pekerjaan setelah lulus.

Hasil penelitian menunjukkan Jenis Kelamin memoderasi hubungan sifat machiavellian dan komitmen profesional dengan memperlemah hubungan antara sifat machiavelian dan komitmen profesional terhadap intensi kecurangan. Dari hasil ini menunjukkan bahwa yang sebelumnya intensi kecurangan dipengaruhi oleh sifat machiavellian, malah tidak dipengaruhi karena adanya jenis kelamin, begitupun dengan komitmen profesional yang makin tidak berpengaruh. Hal ini sejalan dengan penelitian Sarkawi (2015) bahwa tidak ada pengaruh penilaian budaya yang signifikan apabila ditinjau dari variabel jenis kelamin. Peneliti juga berasumsi bahwa niatan dalam melakukan kecurangan bisa dialami semua mahasiswa tanpa melihat jenis kelaminnya, walaupun dengan sifat machiavellian yang tinggi maupun mahasiswa yang memiliki tingkat komitmen yang tinggi maupun untuk tidak melakukan kecurangan.

\section{SIMPULAN DAN SARAN}

Berdasarkan penelitian yang telah dilakukan, diperoleh kesimpulan-kesimpulan sebagai berikut. Pertama, sifat Machiavellian memiliki pengaruh positif terhadap intensi kecurangan akademik. Kedua, komitmen profesional tidak memiliki pengaruh terhadap intensi kecurangan akademik. Ketiga, hasil uji variabel moderasi menunjukkan bahwa variabel jenis kelamin memoderasi atau memperlemah hubungan sifat Machiavellian dan komitmen profesional terhadap intensi kecurangan akademik.

Keterbatasan-keterbatasan dalam penelitian ini diantaranya Obyek penelitian yang terbatas. Penelitian ini hanya dilakukan dengan mengambil sampel pada populasi mahasiswa Akuntansi Fakultas Ekonomika dan Bisnis Universitas Satya Wacana, sehingga tidak dapat disimpulkan bahwa jumlah sampel tersebut mewakili seluruh mahasiswa dan mahasiswi di kota Salatiga, maupun di Indonesia.

Bagi penelitian selanjutnya, agar menambahkan variabel ataupun menggunakan variabel lain dan disarankan untuk menambah ataupun memperluas obyek penelitian agar sampel yang dimiliki lebih variatif dan representatif pada keadaan yang sebenarnya. Sehingga hasil penelitian lebih dapat digenalisir.

\section{DAFTAR PUSTAKA}

Aji, G. (2013). Pengaruh Komitmen Profesional Dan Komitmen Organisasi Terhdap Kinerja Internal Auditor Dengan Etika Kerja Islam Sebagai Variabel Intervening. Jurnal Hukum Islam, 11(1), 103-122.

Amalia, C. R. (2015). Pengaruh Komitmen Organisasi, Komitmen Profesional dan Gaya Kepemimpinan Terhadap Kepuasan 
Kerja Dengan Motivasi Sebagai Variabel Intervening. Journal of Visual Languages $\mathcal{E}$ Computing, 11(3), 287-301.

Bulutoding, Lince, Rika Dwi Ayu Paramitasari, F. H. (2014). Pengaruh Sifat MAchiavellian dan Love of Money Terhadap Perilaku Etis Auditor. Jurnal Akuntansi Peradaban, 3(2), 65-83.

Sarkawi, D. (2015). Pengaruh Jenis Kelamin dan Pengetahuan Lingkungan Terhadap Penilaian Budaya Lingkungan (Studi Ex Post Facto di Akademi Manajemen Informatika dan Komputer Bina Sarana Informatika Jakarta). PLPB: Pendidikan Lingkungan Dan Pembangunan Berkelanjutan, XVI(September), 101-114. https://doi.org/10.21009/PLPB

Dhinata, D. M. (2017). Kepuasan Pelanggan Terhadap Loyalitas Pelanggan Rama Krisna Oleh-Oleh Khas Bali Fakultas Ekonomi dan Bisnis Universitas Udayana ( Unud ), Bali , Indonesia Fakultas Ekonomi dan Bisnis Universitas Udayana, Bali , Indonesia kritik, sehingga dapat menjadi m. Udayana, VII, 2363-2377.

Edwy, F. (2016). Pengaruh Komitmen Organisasional, Komitmen Profesional, Motivasi Kerja, Konflik Peran, Ketidakjelasan Peran dan Kelebihan Peran terhadap Kepuasan Kerja Auditor Pada Kantor Akuntan Publik di Pekanbaru, Padang Dan Batam. JOM Fekon, 3(1), 163-176.

Fitriana, A., \& Baridwan, Z. (2012). Perilaku Kecurangan Mahasiswa Akuntansi-Dimensi Fraud Triangle. Jurnal Akuntansi Multiparadigma.

Marlina, D., Jeremi, F., \& Rukmana, R. (2017). Dilema Etika pada Akuntan - Sebuah Studi Persepsi Mahasiswa Akuntansi. Jurnal Dinamika Dan Akuntansi, 4(2), 159-172.

Nugraha, T. (2017). Pengaruh Komitmen Profesional, Lingkungan Etika, Sifat Machiavellian Dan Personal Dan Personal Cost Terhadap Intensi Whistleblowing Dengan Rentaliasi Sebagai Variabel Moderating. JOM Fekon, 4(1), 2030-2044.

Nurharjanti, N. N. (2017). Persepsi mahasiswa dalam mengurangi fraud akademik: Whistleblowingsistem. Jurnal Akuntansi Dan Bisnis, 17(1), 1-12.

Pemeriksa, B., Keuangan, B. P., \& Indonesia, R. (2017). Standar pemeriksaan keuangan negara.

Riyanti. (2015). Intensi Mencontek Ditinjau Dari
Theory of Planned Behavior. Jurnal Ilmiah Psikologi Terapan, 3(2), 249-267.

Santoso, D. (2015). Pengaruh Perilaku Tidak Jujur dan Kompetensi Moral Terhadap Kecurangan Akademik (Academic Fraud) Mahasiswa Akuntansi. Media Riset Akuntansi, Auditing $\mathcal{E}$ Informasi, 15(1), 1-16.

Simamora, D., Utami, I., Kristen, U., \& Wacana, S. (2017). Intensi Kecurangan Pelaporan Keuangan: Suatu Studi. Indonesian Accounting Research Journal, 5(1), 17-34.

Tangkudung, J. P. M. (2014). Proses Adaptasi Menurut Jenis Kelamin Dalam Menunjang Studi Mahasiswa FISP Universitas Sam Ratulangi. Journal "Acta Diurna," III(4), 111.

Tarbiyah, P. F., Uin, K., Makassar, A., Ibtidaiyah, M., Education, T., Faculty, T. T., \& Makassar, U. I. N. A. (2013). Bentuk kecurangan akademik (nursalam dkk.) 127. Jurnal Lentera Pendidikan, 16(36), 127-138. Retrieved from http://www.uinalauddin.ac.id/download-01 Bentuk Kecurangan Akademik Center.pdf

Widyaningrum, T., \& Sarwono, A. E. (2012). Analisis Sifat Machiavellian dan Pembelajaran Etika Terhadap Sikap Etis Akuntan dan Mahasiswa Akuntansi. Jurnal Akuntansi Dan Sistem Teknologi Informasi, 9(1), 65-75.

Wirakusuma, M. G. (2014). Pengaruh komitmen profesional pada kepuasan kerja auditor dengan motivasi sebagai variabel moderasi. E-Jurnal Manajemen Unud, 2, 210-222.

Yuliana, N. C. (2012). Analisis pengaruh persepsi pentingnya etika dan tanggung jawab sosial, sifat machiavellian, dan keputusan etis terhadap niat berpartisipasi dalam penghindaran pajak. Diponegroro Journal of Accounting, 1, 1-13. 